\title{
BMJ Open Risk of developing multimorbidity across all ages in an historical cohort study: differences by sex and ethnicity
}

\author{
Jennifer L St Sauver, ${ }^{1,2}$ Cynthia M Boyd, ${ }^{3}$ Brandon R Grossardt, ${ }^{4}$ William V Bobo, ${ }^{5}$ \\ Lila J Finney Rutten, ${ }^{1,2}$ Véronique L Roger, ${ }^{1,2,6}$ Jon O Ebbert, ${ }^{2}$ Terry M Therneau, ${ }^{4}$ \\ Barbara P Yawn, ${ }^{1,7}$ Walter A Rocca ${ }^{1,8}$
}

\section{ABSTRACT}

Objective: To study the incidence of de novo multimorbidity across all ages in a geographically defined population with an emphasis on sex and ethnic differences.

Design: Historical cohort study.

Setting: All persons residing in Olmsted County, Minnesota, USA on 1 January 2000 who had granted permission for their records to be used for research $(n=123716)$.

- Prepublication history and additional material is available. To view please visit the journal (http://dx.doi.org/ 10.1136/bmjopen-2014006413).

Received 19 August 2014 Revised 19 December 2014 Accepted 8 January 2015

CrossMark

For numbered affiliations see end of article.

Correspondence to Dr Walter A Rocca; rocca@mayo.edu
Participants: We used the Rochester Epidemiology Project medical records-linkage system to identify all of the county residents. We identified and removed from the cohort all persons who had developed multimorbidity before 1 January 2000 (baseline date), and we followed the cohort over 14 years ( 1 January 2000 through 31 December 2013).

Main outcome measures: Incident multimorbidity was defined as the development of the second of 2 conditions (dyads) from among the 20 chronic conditions selected by the US Department of Health and Human Services. We also studied the incidence of the third of 3 conditions (triads) from among the 20 chronic conditions.

Results: The incidence of multimorbidity increased steeply with older age; however, the number of people with incident multimorbidity was substantially greater in people younger than 65 years compared to people age 65 years or older (28 378 vs 6214 ). The overall risk was similar in men and women; however, the combinations of conditions (dyads and triads) differed extensively by age and by sex. Compared to Whites, the incidence of multimorbidity was higher in Blacks and lower in Asians.

Conclusions: The risk of developing de novo multimorbidity increases steeply with older age, varies by ethnicity and is similar in men and women overall. However, as expected, the combinations of conditions vary extensively by age and sex. These data represent an important first step toward identifying the causes and the consequences of multimorbidity.

\section{INTRODUCTION}

The demographic expansion of the elderly population and the improvements in survival of people affected by chronic conditions have caused a dramatic rise in the number of

\section{Strengths and limitations of this study}

- This is one of the first studies worldwide focusing on the incidence of multimorbidity rather than on the prevalence of multimorbidity. Prevalence reflects the effect of incidence as well as of survival after the onset of multimorbidity. We used a simple definition of incident multimorbidity that can be replicated in other populations.

- This study covered an entire geographically defined population and used a unique records-linkage system. Persons were followed historically over 14 years. None of the data were derived from selfreport or interviews.

- Studies of multimorbidity require the definition of the number of conditions considered, of the time window of occurrence and of the source of data (medical records vs interview). We used the 20 conditions recommended by the US Department of Health and Human Services. These 20 conditions represent a first consensus list; however, not all of the conditions have the same impact on the complexity of care or on the quality of life of patients.

- Potential limitations of this study include the uncertain validity of diagnostic codes, the possible incompleteness of information due to in or out migration and the inability to generalise our findings to other populations with different demographical or social characteristics.

- Replication of this study in other populations in the USA and worldwide will allow for useful comparisons.

people living with multimorbidity ( $\geq 2$ chronic conditions). In the USA, the prevalence of multimorbidity among Medicare recipients increases from $62 \%$ at age $65-74$ years to $82 \%$ at ages 85 years and older. ${ }^{1}$ The monetary costs associated with managing patients with multiple chronic conditions are overwhelming. ${ }^{2-4}$ In addition, fragmented healthcare in patients with multimorbidity causes a particularly high risk for complications and a lower quality of life. ${ }^{56}$ 
Several studies have described the prevalence of multimorbidity in a wide range of populations. ${ }^{1-12}$ Additional studies have focused on how to manage patients with multiple chronic conditions. ${ }^{13}{ }^{14}$ However, in 2010 the US Department of Health and Human Services (US-DHHS) highlighted the critical need to identify groups of individuals at higher risk of developing multimorbidity (first appearance of multimorbidity). Such studies of incident multimorbidity are essential to identify patterns of disease accumulation and to identify the populations at high risk of developing multimorbidity. For example, multimorbidity is highly prevalent in the elderly; however, many of the processes that lead to multimorbidity begin at much earlier ages. Therefore, data on the ages at which multimorbidity begins and on the patterns of accumulation of conditions over time are urgently needed to develop focused interventions to prevent multimorbidities and their adverse health outcomes. ${ }^{15}$

Unfortunately, there are currently no population-based data on the incidence of multimorbidity in the USA across all ages, even though multimorbidity is a high public health priority for the nation. ${ }^{15}$ The Rochester Epidemiology Project (REP) medical records-linkage system captures long-term medical information on a stable population and is therefore uniquely positioned to study the incidence of multimorbidity. In a previous paper, we described in detail the patterns of prevalent multimorbidity in this population. ${ }^{16}$ In this study, we further leveraged this data resource to examine the incidence of multimorbidity across all ages, separately in men and women and in three ethnic groups. ${ }^{17}$

\section{METHODS}

\section{Study population}

The REP has tracked and linked healthcare information for the population of Olmsted County, Minnesota, USA since $1966 .{ }^{17-19}$ The vast majority of medical care in this community is currently provided by a few healthcare institutions: Olmsted Medical Center and its affiliated hospital, Mayo Clinic and its two affiliated hospitals, the Rochester Family Medicine Clinic and a few smaller care facilities. The healthcare records from these institutions are linked together through the REP records-linkage system. ${ }^{17-19}$ Persons are considered residents of Olmsted County at the time of each healthcare visit based on their address. Over the years, this address information has been accumulated and is used to define who resided in Olmsted County at any given point in time since 1966 (REP Census). The population counts obtained by the REP Census are similar to those obtained by the US Census, indicating that virtually the entire population of the county is captured by the system. ${ }^{18-20}$ We used the REP Census to identify all individuals who resided in Olmsted County on 1 January 2000 (baseline date); however, we included only individuals who had not refused permission to use their medical records for research (Minnesota Research Authorization). ${ }^{18} 2122$

\section{Definition of incident multimorbidity}

We focused on 20 selected chronic conditions recommended by the US-DHHS for studying multimorbidity. ${ }^{2324}$ The list of the 20 conditions and the corresponding International Classification of Diseases Ninth Edition (ICD-9) codes used in this study are provided in online supplementary table SA. ${ }^{23}{ }^{24}$ We first identified all ICD-9 codes associated with these 20 chronic conditions that occurred in the population between 1 January 1995 and 31 December 1999 ( 5 years before the baseline date, 1 January 2000). Persons who did not have any ICD-9 codes for a given condition were assumed to not have the condition of interest. By contrast, residents were defined as having a chronic condition if they had at least two ICD-9 codes for that condition separated by more than 30 days, and the incidence date was assigned at the time they received a second diagnostic code.

Persons who had 2 or more of the 20 conditions at baseline were considered to have prevalent multimorbidity and were therefore excluded from incidence analyses of 2 chronic conditions (dyads). Similarly, persons who had 3 or more of the 20 conditions at baseline were excluded from incidence analyses of 3 chronic conditions (triads). All persons in this fixed population cohort were followed historically through the REP records-linkage system for approximately 14 years to study the emergence of new conditions.

\section{Statistical analyses}

All persons in the cohort were followed from 1 January 2000 through the last contact with the records-linkage system (the earliest of death date, last medical visit date or 31 December 2013). The incidence of each of the 20 chronic conditions was calculated among persons free of that condition at baseline. Persons contributed personyears to the denominator for the incidence of two conditions (development of a second condition in a dyad) only during the time when they had zero or one chronic conditions, whereas persons contributed person-years to the denominator for the incidence of three chronic conditions (development of a third condition in a triad) only when they had zero, one or two chronic conditions. Although the majority of people accumulated conditions one-at-a-time, some participants jumped from zero to two conditions, or from one to three, or even from zero to three conditions. For example, a person previously considered free of all of the 20 conditions who was diagnosed with hyperlipidaemia, hypertension and depression during one visit was counted as having three incident dyads and one incident triad on the same date.

Incidence rates were reported separately by age (using seven age strata or splitting the entire population in $0-64$ and $\geq 65$ years), sex and ethnicity, and were directly standardised by age and sex to the total US 2010 Decennial Census after removing projected prevalence (see online supplementary table SB). Since the study covered the target population completely, and no sampling was involved, CIs were not included in the 
tables. ${ }^{25}{ }^{26}$ Ethnicity data were not available for 9176 people $(7.4 \%$ of the cohort). These individuals were included in the overall and age-specific and sex-specific analyses, but not in the ethnicity-specific analyses.

Although the 20 conditions proposed by the US-DHHS represent a national consensus, ${ }^{15}$ some of the conditions may have a different prognostic impact than others. For example, hyperlipidaemia and hypertension often occur together and tend to remain asymptomatic. Therefore, we performed a set of sensitivity analyses combining hyperlipidaemia and hypertension as a single chronic condition. The date of incidence for the single chronic condition of hyperlipidaemia and/or hypertension was defined as the date the person first met criteria for either of these conditions.

\section{RESULTS}

Description of the OImsted County population

The REP Census identified 129311 Olmsted County, Minnesota residents on 1 January 2000 compared with 124277 individuals counted by the 2000 US Census (104.1\%); 123716 persons provided Minnesota research authorisation for medical record research $(95.7 \%)$ and were included in our analyses. A total of 17655 people $(14.3 \%)$ had two or more conditions at the baseline date and $9368(7.6 \%)$ had three or more conditions (prevalent multimorbidity). Overall, we observed a total of 1334906 person-years of follow-up; however, as expected, the length of follow-up varied by age group. For example, median follow-up was 13.1 years in persons aged $0-19$ years at baseline, 12.3 years in persons aged 70-79 years at baseline and 4.9 years in persons aged 80 years or older at baseline.

Figure 1 and online supplementary table SC report the incidence of each of the 20 chronic conditions considered separately by age and sex. The incidence of most of the chronic conditions increased steeply with older age. However, the incidence of asthma, substance abuse disorders, hepatitis, autism spectrum disorder and infection with HIV was higher in the younger population compared to persons older than 60 years. The incidence of depression increased from ages $0-19$ to 20-39 years, declined from 40-49 to 60-69 years, and increased sharply again thereafter. The incidence of most conditions was higher in men compared to women of the same age; however, women had a higher incidence of depression, arthritis, asthma and osteoporosis. The incidence curves in men and women crossed at age 50-59 years for cancer and at age 60-69 years for chronic obstructive pulmonary disease (figure 1 ).

\section{Incidence of multimorbidity by age, sex and ethnicity}

Figure 2 shows the age-specific incidence rates of multimorbidity in men and women separately (A and $\mathrm{C}$ ), and in three ethnic groups (B and D). The incidence of two chronic conditions and the incidence of three chronic conditions both increased steeply with older age (table 1 , table 2, and figure 2). For example, the incidence of two chronic conditions in men was 6.5/1000 person-years in persons who were ages $0-19$ years, and 260.0/1000 in persons who were $\geq 80$ years. The overall incidence of two chronic conditions was slightly higher in women compared to men (overall standardised incidence rates 38.8 vs 35.5/1000 person-years; table 1). The incidence of two chronic conditions was higher in Blacks compared to Whites, but lower in Asians compared to Whites (see standardised incidence rates in table 1 and figure 2). We observed similar patterns for the development of three chronic conditions (see standardised incidence rates in table 2 and figure 2). The overall incidence of three conditions was similar in men and women (standardised incidence rates 25.5/1000 person-years in men vs 26.6/1000 person-years in women); however, it was higher in Blacks and lower in Asians, compared to Whites (table 2 and figure 2).

In the set of sensitivity analyses in which we combined hyperlipidaemia and hypertension as a single condition, we observed a slight decrease in the incidence of two chronic conditions and of three chronic conditions compared with the primary analyses. The overall incidence rate of two conditions decreased from 35.0 to $34.0 / 1000$ person-years in men and from 40.3 to $40.0 / 1000$ personyears in women. The incidence rate of three conditions decreased from 24.7 to $22.5 / 1000$ person-years in men and from 28.5 to $27.0 / 1000$ person-years in women (incidence rates non-standardised; data not shown in the tables). For both two and three conditions, the decrease in incidence was more sizeable in men than in women.

\section{Incidence of dyads and triads}

Table 3 shows the incidence of the most common dyads or triads of chronic conditions in seven age strata and for men and women separately. As expected, the incidence of dyads and triads varied extensively with age. For example, the most common incident dyad in persons 0-19 years was depression and asthma (1.8/1000 personyears in boys or men and 2.9/1000 person-years in girls or women). By comparison, the most common dyad in persons $\geq 80$ years was hypertension and cancer in men (18.9/1000 person-years), and hypertension and arthritis in women $(27.7 / 1000$ person-years $)$. Similarly, the most common incident triad of conditions in persons aged 0-19 years was depression, asthma and substance abuse disorders in both sexes. By comparison, the most common incident triads in persons $\geq 80$ years were hypertension, cancer and arrhythmia in men, and hyperlipidaemia, hypertension and arthritis in women.

As expected, the incidence of dyads and triads also varied by sex. In some instances, the composition of the dyads or triads was the same for men and women, but the magnitude of the incidence rate was different. In other instances, the magnitude of the incidence rate was similar in men and women, but the composition of the dyads and triads varied by sex. For example, the most 

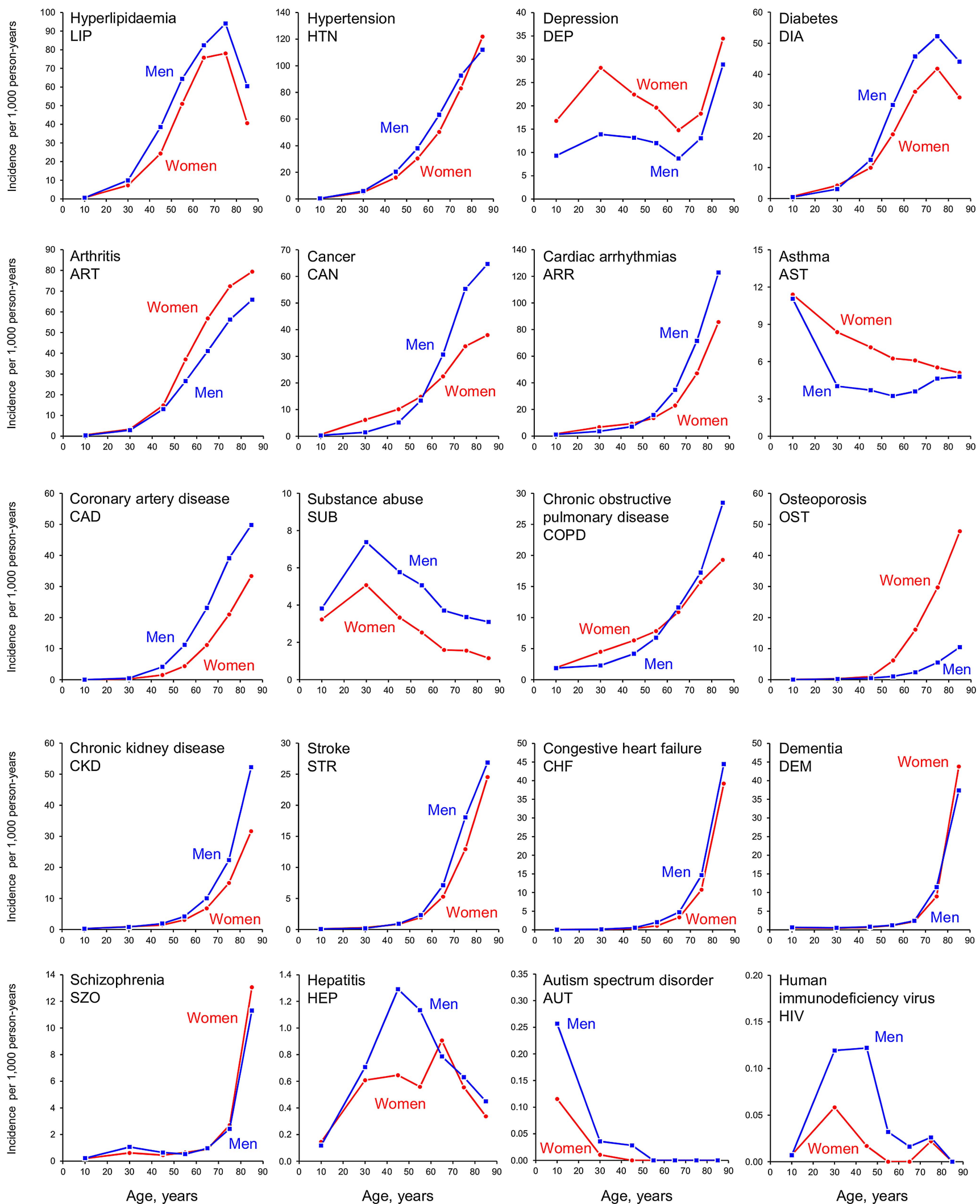

Figure 1 Age-specific and sex-specific incidence rates (per 1000 person-years) of the 20 chronic conditions considered separately. The 20 panels are presented by rows in decreasing order of frequency (by overall age-standardised and sex-standardised prevalence). ${ }^{16}$

common incident dyad in persons aged 60-69 years was hyperlipidaemia and hypertension in both sexes, but the incidence rate was higher in men compared to women $(23.4 / 1000$ person-years vs $18.8 / 1000$ personyears). By contrast, the incidence rates of the most common triads in persons aged 60-69 years were similar 

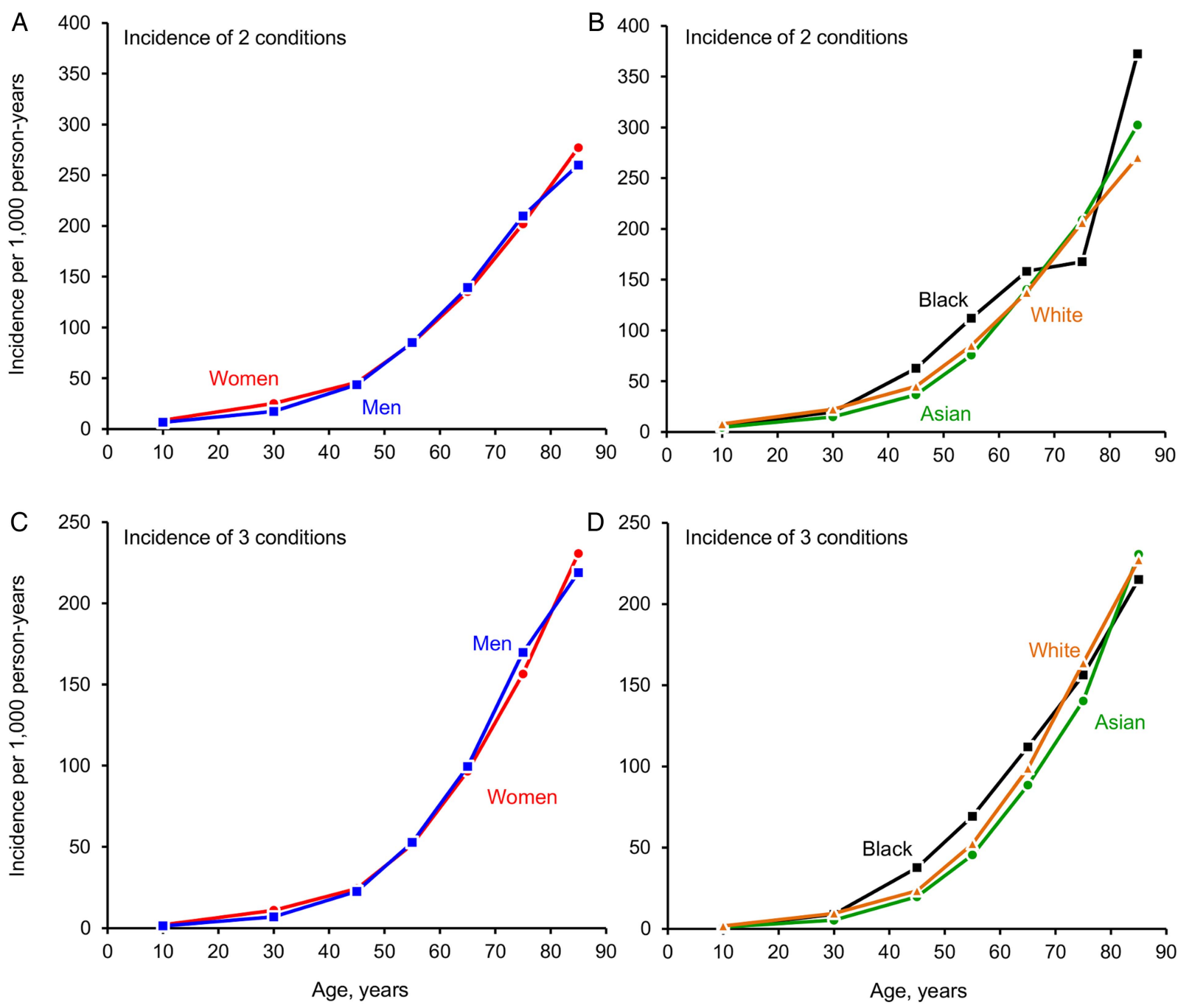

Figure 2 Incidence rates (per 1000 person-years) of two chronic conditions (second condition in a dyad) and of three chronic conditions (third condition in a triad) in men and women separately ( $A$ and $C)$, and stratified by ethnicity (B and $D)$.

in men and women $(11.6 / 1000$ vs $10.3 / 1000$ personyears); however, they included different conditions (table 3).

\section{DISCUSSION}

\section{Statement of the principal findings}

The burden of multimorbidity in the USA is high, and is increasing with an aging population and with improvements in survival. We leveraged a unique longitudinal data resource covering an entire, stable and geographically defined population to examine the incidence of multimorbidity across all ages. The incidence of two chronic conditions and the incidence of three chronic conditions increased steeply with older age, and the overall risk was similar in men and women. However, the number of people who developed multimorbidity before age 65 was more than four times greater than the number of people who developed multimorbidity after age 65 (28 378 vs 6214; table 2). The incidence of multimorbidity was highest in Blacks and lowest in Asians. Finally, as expected, the combinations of conditions in incident dyads and triads differed extensively by age and by sex. These results have important implications for identifying individuals at higher risk of developing multimorbidity at different ages. These data are also a first step toward understanding the causes and the consequences of multimorbidity.

\section{Strengths and limitations}

A unique strength of our study was the ability to measure the incidence of multimorbidity documented in medical records across seven age groups and for an entire, geographically defined population. We used historical data to exclude individuals with prevalent multimorbidity at baseline as well as to follow individuals over a long period of time to accurately document the development of incident multimorbidity. In total, our findings reflect 19 years of data accumulation ( 5 years before and 14 years after the baseline date).

Unfortunately, there is no standard definition of multimorbidity. Previous studies have included a wide range of chronic conditions and a wide range of time frames. We defined multimorbidity using the 20 conditions 
Table 1 Incidence of the second of two chronic conditions (per 1000 person-years) in persons living in Olmsted County, Minnesota, by age, sex and ethnicity

\begin{tabular}{|c|c|c|c|c|c|c|}
\hline \multirow[b]{2}{*}{ Ethnicity age (years) } & \multicolumn{3}{|l|}{ Men } & \multicolumn{3}{|l|}{ Women } \\
\hline & Persons & Person-years & Incidence rate* $(n)$ & Persons & Person-years & Incidence rate ${ }^{\star}(\mathrm{n})$ \\
\hline \multicolumn{7}{|l|}{ All ethnic groups } \\
\hline $0-19$ & 18879 & 140653 & $6.5(921)$ & 18024 & 134725 & $8.5(1151)$ \\
\hline $20-39$ & 27732 & 151734 & $17.2(2613)$ & 28571 & 158252 & 25.1 (3972) \\
\hline $40-49$ & 16396 & 82324 & $43.6(3590)$ & 16713 & 85660 & 45.8 (3920) \\
\hline $50-59$ & 11779 & 52085 & $85.2(4436)$ & 12398 & 55270 & 84.6 (4674) \\
\hline $60-69$ & 5218 & 19653 & 139.4 (2739) & 5603 & 21246 & $135.3(2874)$ \\
\hline $70-79$ & 1775 & 5451 & $209.9(1144)$ & 2184 & 6660 & $202.0(1345)$ \\
\hline$\geq 80$ & 531 & 1589 & $260.0(413)$ & 1016 & 2887 & $277.1(800)$ \\
\hline$\overline{0}-64$ & 50648 & 439254 & 29.7 (13 059) & 51056 & 447399 & 34.2 (15 319) \\
\hline$\geq 65$ & 3794 & 14236 & 196.5 (2797) & 4636 & 17300 & $197.5(3417)$ \\
\hline All ages & 52479 & 453489 & $35.0(15856)$ & 53582 & 464699 & $40.3(18736)$ \\
\hline Standardised $\dagger$ & - & - & 35.5 & - & - & 38.8 \\
\hline \multicolumn{7}{|l|}{ Blacks } \\
\hline $0-19$ & 877 & 6411 & $5.5(35)$ & 749 & 5362 & $6.0(32)$ \\
\hline $20-39$ & 1099 & 6178 & $16.5(102)$ & 934 & 5647 & $23.0(130)$ \\
\hline $40-49$ & 429 & 1836 & $63.2(116)$ & 324 & 1392 & $61.8(86)$ \\
\hline $50-59$ & 180 & 683 & $105.3(72)$ & 139 & 513 & $121.0(62)$ \\
\hline $60-69$ & 60 & 223 & $134.8(30)$ & 47 & 150 & $193.2(29)$ \\
\hline $70-79$ & 18 & 71 & $140.1(10)$ & 23 & 60 & $200.4(12)$ \\
\hline$\geq 80$ & 4 & 11 & $274.0(3)$ & 3 & 5 & $580.3(3)$ \\
\hline$\overline{0}-64$ & 1848 & 15240 & 22.0 (335) & 1563 & 13010 & 25.5 (332) \\
\hline$\geq 65$ & 48 & 173 & $190.8(33)$ & 37 & 118 & $185.7(22)$ \\
\hline All ages & 1873 & 15413 & $23.9(368)$ & 1587 & 13128 & $27.0(354)$ \\
\hline Standardised $\dagger$ & - & - & 38.9 & - & - & 48.5 \\
\hline \multicolumn{7}{|l|}{ Asians } \\
\hline $0-19$ & 818 & 6331 & 3.5 (22) & 826 & 6299 & $5.6(35)$ \\
\hline $20-39$ & 1090 & 6372 & $15.1(96)$ & 1168 & 7167 & $14.6(105)$ \\
\hline $40-49$ & 534 & 2464 & $39.8(98)$ & 591 & 2869 & $33.8(97)$ \\
\hline $50-59$ & 339 & 1588 & $71.8(114)$ & 376 & 1687 & $79.4(134)$ \\
\hline $60-69$ & 159 & 592 & $120.0(71)$ & 185 & 570 & $161.3(92)$ \\
\hline $70-79$ & 51 & 163 & $140.8(23)$ & 74 & 177 & $271.6(48)$ \\
\hline$\geq 80$ & 21 & 60 & $216.6(13)$ & 40 & 92 & $358.1(33)$ \\
\hline$\overline{0}-64$ & 1897 & 17137 & $21.6(370)$ & 1997 & 18399 & $23.3(429)$ \\
\hline$\geq 65$ & 114 & 433 & $154.7(67)$ & 159 & 463 & $248.4(115)$ \\
\hline All ages & 1954 & 17571 & $24.9(437)$ & 2105 & 18862 & $28.8(544)$ \\
\hline Standardised $\dagger$ & - & - & 29.5 & - & - & 34.9 \\
\hline \multicolumn{7}{|l|}{ Whites } \\
\hline $0-19$ & 14956 & 119686 & $6.8(818)$ & 14414 & 114906 & $9.0(1032)$ \\
\hline 20-39 & 21792 & 128801 & 17.9 (2303) & 23214 & 135903 & 26.5 (3599) \\
\hline $40-49$ & 14426 & 74921 & 43.6 (3269) & 15088 & 79123 & 46.1 (3646) \\
\hline $50-59$ & 10795 & 48361 & 85.8 (4149) & 11520 & 51901 & 84.8 (4399) \\
\hline $60-69$ & 4823 & 18362 & $140.4(2578)$ & 5221 & 20075 & $134.7(2704)$ \\
\hline $70-79$ & 1653 & 5090 & 212.6 (1082) & 2030 & 6301 & 200.9 (1266) \\
\hline$\geq 80$ & 497 & 1495 & $262.8(393)$ & 953 & 2754 & $274.5(756)$ \\
\hline$\overline{0}-64$ & 40703 & 383410 & 31.2 (11 952) & 42149 & 394566 & $35.9(14170)$ \\
\hline$\geq 65$ & 3517 & 13306 & $198.4(2640)$ & 4317 & 16398 & 197.1 (3232) \\
\hline All ages & 42382 & 396716 & 36.8 (14 592) & 44465 & 410964 & 42.3 (17 402) \\
\hline Standardised $\dagger$ & - & - & 36.0 & - & - & 39.4 \\
\hline
\end{tabular}

*Incidence rates are reported per 1000 person-years.

†Incidence rates were directly standardised to the total US population from the 2010 US Decennial Census after removing the number of people with prevalent multimorbidity ( $\geq 2$ chronic conditions) as projected from our previous study (see online supplementary table SB). ${ }^{16}$

selected by US-DHHS, which were chosen because they 'meet the definition for chronicity, are prevalent [common], and are potentially amenable to public health or clinical interventions or both. ${ }^{, 23}$ However, this definition provides equal weight to each of the 20 conditions without considering the impact of combinations of specific conditions on the quality of life of patients, the complexity of their joint management and the severity 
Table 2 Incidence of the third of three chronic conditions (per 1000 person-years) in persons living in Olmsted County, Minnesota, by age, sex and ethnicity

\begin{tabular}{|c|c|c|c|c|c|c|}
\hline \multirow[b]{2}{*}{ Ethnicity age (years) } & \multicolumn{3}{|l|}{ Men } & \multicolumn{3}{|l|}{ Women } \\
\hline & Persons & Person-years & ${\text { Incidence } \text { rate }^{*}(\mathrm{n})}$ & Persons & Person-years & Incidence rate* (n) \\
\hline \multicolumn{7}{|l|}{ All ethnic groups } \\
\hline $0-19$ & 19029 & 144025 & $1.3(186)$ & 18203 & 138055 & $2.0(282)$ \\
\hline 20-39 & 28721 & 162693 & $6.9(1123)$ & 30135 & 177878 & $10.9(1944)$ \\
\hline $40-49$ & 17901 & 95582 & $22.6(2157)$ & 18824 & 103400 & $24.2(2507)$ \\
\hline $50-59$ & 14398 & 69907 & $52.8(3688)$ & 15475 & 76247 & $51.5(3930)$ \\
\hline $60-69$ & 7517 & 31617 & 99.5 (3146) & 8313 & 35342 & 96.7 (3416) \\
\hline $70-79$ & 3109 & 10639 & 169.7 (1805) & 3899 & 13653 & $156.4(2136)$ \\
\hline$\geq 80$ & 992 & 3230 & $218.9(707)$ & 1970 & 6414 & 230.6 (1479) \\
\hline $0-64$ & 53073 & 491536 & $18.0(8852)$ & 54280 & 517164 & $20.2(10432)$ \\
\hline$\geq 65$ & 5938 & 26156 & $151.4(3960)$ & 7706 & 33825 & $155.6(5262)$ \\
\hline All ages & 55898 & 517693 & 24.7 (12 812) & 58450 & 550989 & $28.5(15694)$ \\
\hline Standardised $†$ & - & - & 25.5 & - & - & 26.6 \\
\hline \multicolumn{7}{|l|}{ Blacks } \\
\hline $0-19$ & 879 & 6530 & $1.1(7)$ & 751 & 5458 & $1.1(6)$ \\
\hline 20-39 & 1123 & 6428 & $8.6(55)$ & 960 & 6032 & $9.4(57)$ \\
\hline $40-49$ & 460 & 2126 & $34.8(74)$ & 373 & 1723 & $41.2(71)$ \\
\hline $50-59$ & 218 & 952 & $69.3(66)$ & 173 & 737 & $69.2(51)$ \\
\hline $60-69$ & 81 & 312 & 96.1 (30) & 70 & 241 & $132.8(32)$ \\
\hline $70-79$ & 27 & 108 & $129.4(14)$ & 28 & 84 & $191.0(16)$ \\
\hline$\geq 80$ & 5 & 23 & $172.3(4)$ & 5 & 9 & $321.2(3)$ \\
\hline $0-64$ & 1883 & 16227 & $13.3(216)$ & 1602 & 14101 & $14.5(205)$ \\
\hline$\geq 65$ & 58 & 252 & $135.1(34)$ & 54 & 183 & $169.2(31)$ \\
\hline All ages & 1911 & 16479 & $15.2(250)$ & 1633 & 14284 & $16.5(236)$ \\
\hline Standardised $†$ & - & - & 28.2 & - & - & 34.8 \\
\hline \multicolumn{7}{|l|}{ Asians } \\
\hline $0-19$ & 823 & 6419 & $0.6(4)$ & 832 & 6442 & $1.6(10)$ \\
\hline 20-39 & 1109 & 6747 & $6.2(42)$ & 1206 & 7587 & $4.6(35)$ \\
\hline $40-49$ & 574 & 2841 & $18.7(53)$ & 651 & 3327 & 20.7 (69) \\
\hline $50-59$ & 390 & 1942 & $44.8(87)$ & 439 & 2191 & $46.1(101)$ \\
\hline $60-69$ & 203 & 830 & 78.3 (65) & 254 & 966 & $97.3(94)$ \\
\hline $70-79$ & 80 & 259 & $138.8(36)$ & 110 & 353 & $141.5(50)$ \\
\hline$\geq 80$ & 32 & 84 & $202.0(17)$ & 84 & 228 & $241.2(55)$ \\
\hline$\overline{0}-64$ & 1940 & 18472 & 12.2 (225) & 2074 & 20167 & $12.9(261)$ \\
\hline$\geq 65$ & 165 & 650 & $121.5(79)$ & 258 & 929 & 164.7 (153) \\
\hline All ages & 2027 & 19122 & $15.9(304)$ & 2235 & 21096 & $19.6(414)$ \\
\hline Standardised $†$ & - & - & 21.1 & - & - & 23.2 \\
\hline \multicolumn{7}{|l|}{ Whites } \\
\hline $0-19$ & 15088 & 122717 & $1.3(160)$ & 14576 & 117885 & 2.2 (259) \\
\hline 20-39 & 22681 & 138725 & 7.1 (990) & 24638 & 154160 & 11.7 (1799) \\
\hline $40-49$ & 15811 & 87199 & 22.7 (1978) & 17025 & 95693 & 24.1 (2308) \\
\hline $50-59$ & 13262 & 65243 & 53.1 (3464) & 14443 & 71770 & 51.7 (3714) \\
\hline $60-69$ & 7028 & 29816 & 100.8 (3005) & 7796 & 33477 & 96.9 (3244) \\
\hline $70-79$ & 2930 & 10061 & 171.9 (1729) & 3680 & 13006 & $157.2(2045)$ \\
\hline$\geq 80$ & 942 & 3093 & $219.5(679)$ & 1848 & 6105 & $231.0(1410)$ \\
\hline $0-64$ & 42953 & 432089 & 19.0 (8213) & 45157 & 459919 & $21.2(9761)$ \\
\hline$\geq 65$ & 5572 & 24764 & 153.1 (3792) & 7224 & 32177 & $155.9(5018)$ \\
\hline All ages & 45583 & 456853 & $26.3(12$ 005) & 49033 & 492097 & 30.0 (14 779) \\
\hline Standardised $†$ & - & - & 25.7 & - & - & 27.0 \\
\hline
\end{tabular}

*Incidence rates are reported per 1000 person-years.

†Incidence rates were directly standardised to the total US population from the 2010 US Decennial Census after removing the number of people with prevalent multimorbidity ( $\geq 3$ chronic conditions) as projected from our previous study (see online supplementary table SB). ${ }^{16}$

of their long-term outcomes. In addition, this list does not include a number of conditions that may have a significant impact on the burden of multimorbidity in older participants (eg, hearing and vision problems).
Such conditions should be considered in future studies of multimorbidity. By contrast, the list includes some conditions that were less common in the general population. For example, autism appeared as part of an 
Table 3 Incidence rates (per 1000 person-years) and composition of the most common dyads and triads of chronic conditions in persons living in Olmsted County, Minnesota, by age and sex.

\begin{tabular}{|c|c|c|c|c|c|c|c|c|}
\hline \multirow{3}{*}{$\begin{array}{l}\text { Age } \\
\text { (years) } \\
\text { Rank * }\end{array}$} & \multicolumn{4}{|l|}{ Dyad } & \multicolumn{4}{|l|}{ Triad } \\
\hline & \multicolumn{2}{|l|}{ Men } & \multicolumn{2}{|l|}{ Women } & \multicolumn{2}{|l|}{$\overline{\text { Men }}$} & \multicolumn{2}{|l|}{ Women } \\
\hline & Combination† & Rate (n)‡ & Combination† & Rate (n)‡ & Combination† & Rate $(\mathrm{n}) \S$ & Combination† & Rate (n)§ \\
\hline \multicolumn{9}{|l|}{$0-19$} \\
\hline 1 & DEP_AST & $1.8(257)$ & DEP_AST & $2.9(395)$ & DEP_AST—SUB & $0.4(53)$ & DEP—AST—SUB & $0.4(62)$ \\
\hline 2 & DEP-SUB & $1.3(178)$ & DEP-SUB & $1.8(240)$ & DEP-AST-COPD & $0.1(17)$ & DEP-AST—COPD & $0.3(39)$ \\
\hline 3 & AST-COPD & $0.9(122)$ & AST-COPD & $0.7(91)$ & DEP-SUB-SZO & $0.1(8)$ & DEP-ARR—AST & $0.2(27)$ \\
\hline 4 & AST_SUB & $0.4(56)$ & DEP-ARR & $0.4(50)$ & LIP-DEP-AST & $<0.1(7)$ & DEP-ARR-SUB & $0.1(13)$ \\
\hline 5 & DEP-ARR & $0.1(21)$ & DEP_COPD & $0.4(48)$ & 3-way tieף & $<0.1(6)$ & DEP-SUB-COPD & $0.1(12)$ \\
\hline \multicolumn{9}{|l|}{$20-39$} \\
\hline 1 & DEP-SUB & $3.5(525)$ & DEP—AST & $3.4(531)$ & DEP-AST—SUB & $0.4(73)$ & DEP-AST—SUB & $0.8(134)$ \\
\hline 2 & LIP-HTN & $1.4(207)$ & DEP_SUB & $2.9(463)$ & DEP_SUB-SZO & $0.4(69)$ & DEP_AST_COPD & $0.7(121)$ \\
\hline 3 & DEP-AST & $1.1(174)$ & DEP-CAN & $2.0(309)$ & LIP-HTN-DIA & $0.4(65)$ & DEP-ARR-AST & $0.4(77)$ \\
\hline 4 & LIP_DEP & $1.0(155)$ & LIP—DEP & $1.7(267)$ & DEP_ARR-SUB & $0.3(46)$ & DEP-SUB-COPD & $0.3(61)$ \\
\hline 5 & LIP_DIA & $0.9(137)$ & DEP-ARR & $1.4(222)$ & LIP-HTN-DEP & $0.3(45)$ & LIP-DEP-AST & $0.3(58)$ \\
\hline \multicolumn{9}{|l|}{$40-49$} \\
\hline 1 & LIP-HTN & $7.0(580)$ & LIP-DEP & $4.1(354)$ & LIP-HTN-DIA & $3.1(294)$ & LIP-HTN-DIA & $1.4(147)$ \\
\hline 2 & LIP_DIA & $4.4(363)$ & LIP-HTN & $3.6(308)$ & LIP-HTN-DEP & $1.2(115)$ & LIP-HTN-DEP & $1.1(114)$ \\
\hline 3 & LIP-DEP & $3.5(285)$ & DEP-ART & $2.6(224)$ & LIP_HTN-ART & $0.9(84)$ & LIP-DEP-DIA & $1.0(99)$ \\
\hline 4 & LIP-ART & $2.4(198)$ & DEP-CAN & $2.6(224)$ & LIP-HTN-CAD & $0.9(83)$ & LIP-DEP-ART & $0.8(84)$ \\
\hline 5 & DEP—SUB & $1.9(157)$ & HTN—DEP & $2.4(203)$ & LIP-DEP-DIA & $0.8(74)$ & LIP-DEP-AST & $0.6(63)$ \\
\hline \multicolumn{9}{|l|}{$50-59$} \\
\hline 1 & LIP-HTN & $14.5(757)$ & LIP-HTN & $9.8(540)$ & LIP-HTN-DIA & $7.2(504)$ & LIP-HTN-DIA & $3.9(300)$ \\
\hline 2 & LIP_DIA & $8.7(455)$ & LIP-ART & 6.5 (359) & LIP-HTN-ART & $3.5(242)$ & LIP-HTN-ART & $3.0(232)$ \\
\hline 3 & LIP-ART & $6.7(351)$ & LIP-DEP & 5.9 (325) & LIP-HTN-CAD & $3.0(208)$ & LIP-HTN-DEP & 2.4 (185) \\
\hline 4 & LIP-CAN & $4.6(241)$ & DEP-ART & $4.8(265)$ & LIP-HTN-DEP & $1.9(131)$ & LIP-DEP-ART & $2.4(180)$ \\
\hline 5 & HTN-DIA & $4.4(227)$ & LIP-CAN & $4.5(246)$ & LIP-HTN-ARR & $1.7(117)$ & LIP-HTN-CAN & $1.8(136)$ \\
\hline \multicolumn{9}{|l|}{$60-69$} \\
\hline 1 & LIP-HTN & $23.4(460)$ & LIP-HTN & $18.8(400)$ & LIP-HTN-DIA & $11.6(366)$ & LIP-HTN-ART & $10.3(363)$ \\
\hline 2 & LIP-DIA & $11.5(226)$ & LIP-ART & $15.5(330)$ & LIP-HTN-ART & $6.8(214)$ & LIP-HTN-DIA & $7.4(263)$ \\
\hline 3 & LIP-ART & 11.4 (224) & HTN-ART & $10.4(220)$ & LIP-HTN-CAD & $6.3(200)$ & LIP-HTN-CAN & $4.6(164)$ \\
\hline 4 & LIP-CAN & $10.0(196)$ & LIP-CAN & $6.8(145)$ & LIP-HTN-CAN & $4.9(155)$ & LIP-ART-CAN & $2.9(102)$ \\
\hline 5 & HTN-DIA & 8.6 (169) & LIP_DIA & 6.4 (135) & LIP_HTN-ARR & 3.4 (106) & LIP_DIA-ART & $2.7(95)$ \\
\hline 6 & HTN-ART & $7.7(152)$ & ART-CAN & $4.9(105)$ & LIP-DIA-ART & $2.9(91)$ & LIP-HTN-DEP & $2.6(93)$ \\
\hline 7 & LIP-CAD & $6.9(136)$ & LIP-OST & $4.9(105)$ & LIP-ART-CAN & $2.6(82)$ & LIP-DEP-ART & $2.5(89)$ \\
\hline 8 & HTN-CAN & $6.2(121)$ & HTN-CAN & $4.8(103)$ & LIP-DIA-CAD & $2.4(76)$ & LIP_ART-ARR & $2.3(83)$ \\
\hline 9 & ART-CAN & $4.5(89)$ & HTN-DIA & $4.6(97)$ & HTN-DIA-ART & $2.2(71)$ & LIP-HTN-OST & $2.2(79)$ \\
\hline 10 & LIP_ARR & $4.5(88)$ & LIP_DEP & $4.4(94)$ & LIP-ARR-CAD & $2.2(68)$ & HTN-DIA-ART & $2.2(77)$ \\
\hline \multicolumn{9}{|l|}{$70-79$} \\
\hline 1 & LIP-HTN & 19.1 (104) & LIP-HTN & $26.0(173)$ & LIP-HTN-CAN & $11.9(127)$ & LIP-HTN-ART & $15.7(214)$ \\
\hline 2 & $\mathrm{HTN}-\mathrm{CAN}$ & $18.9(103)$ & HTN-ART & 18.5 (123) & LIP-HTN-DIA & 10.4 (111) & LIP-HTN-DIA & $9.8(134)$ \\
\hline 3 & LIP-CAN & $15.0(82)$ & LIP-ART & $15.5(103)$ & LIP-HTN-CAD & $9.7(103)$ & LIP-HTN-CAN & $6.0(82)$ \\
\hline 4 & HTN-ART & $13.2(72)$ & LIP-OST & $9.0(60)$ & LIP-HTN-ART & $9.4(100)$ & LIP-ART-CAN & $5.4(74)$ \\
\hline 5 & ART-CAN & $11.6(63)$ & HTN-CAN & $8.9(59)$ & LIP-HTN-ARR & $5.5(58)$ & HTN-ART-CAN & $5.2(71)$ \\
\hline 6 & LIP-ART & $11.6(63)$ & HTN-OST & $8.3(55)$ & HTN-ART-CAN & $4.9(52)$ & LIP_ART—OST & $5.2(71)$ \\
\hline
\end{tabular}




\begin{tabular}{|c|c|c|c|c|c|c|c|c|}
\hline \multirow{3}{*}{$\begin{array}{l}\text { Age } \\
\text { (years) } \\
\text { Rank * }\end{array}$} & \multicolumn{4}{|l|}{ Dyad } & \multicolumn{4}{|l|}{ Triad } \\
\hline & \multicolumn{2}{|l|}{ Men } & \multicolumn{2}{|l|}{ Women } & \multicolumn{2}{|l|}{ Men } & \multicolumn{2}{|l|}{ Women } \\
\hline & Combination† & Rate (n)‡ & Combination† & Rate $(\mathrm{n}) \ddagger$ & Combination† & Rate $(\mathbf{n}) \S$ & Combination† & Rate $(n) \S$ \\
\hline 7 & HTN-DIA & $10.1(55)$ & ART-CAN & $8.1(54)$ & LIP-ART—CAN & $4.7(50)$ & LIP-HTN-OST & $4.6(63)$ \\
\hline 8 & HTN-ARR & $9.9(54)$ & ART-OST & $7.8(52)$ & HTN-CAN-ARR & $4.2(45)$ & LIP-HTN-ARR & $4.5(62)$ \\
\hline 9 & LIP-CAD & $7.7(42)$ & HTN-DIA & $7.8(52)$ & HTN-ART-ARR & $4.1(44)$ & HTN-ART-OST & $4.0(55)$ \\
\hline 10 & LIP—DIA & $7.7(42)$ & LIP-CAN & $7.8(52)$ & LIP-DIA-CAN & $4.1(44)$ & 2-way tie ${ }^{\star *}$ & $3.4(47)$ \\
\hline \multicolumn{9}{|l|}{$\geq 80$} \\
\hline 1 & HTN-CAN & $18.9(30)$ & HTN-ART & $27.7(80)$ & HTN-CAN-ARR & $8.7(28)$ & LIP-HTN-ART & $10.3(66)$ \\
\hline 2 & HTN-ARR & $17.6(28)$ & LIP—HTN & $23.2(67)$ & LIP-HTN-CAN & $7.7(25)$ & HTN—ART—OST & $9.8(63)$ \\
\hline 3 & HTN-ART & $14.5(23)$ & HTN-ARR & $17.7(51)$ & HTN-ART-CAN & $7.4(24)$ & HTN-ART-CAN & $9.2(59)$ \\
\hline 4 & ART-ARR & $12.0(19)$ & HTN-CAN & $15.2(44)$ & LIP-HTN-ART & $6.2(20)$ & HTN-ART_ARR & $9.0(58)$ \\
\hline 5 & CAN-ARR & $12.0(19)$ & HTN-OST & $14.9(43)$ & LIP-HTN-ARR & $5.9(19)$ & LIP-HTN-OST & $5.9(38)$ \\
\hline 6 & HTN-CAD & $10.1(16)$ & HTN-DEM & $11.8(34)$ & ART-CAN-ARR & $5.3(17)$ & LIP_HTN-DIA & $5.0(32)$ \\
\hline 7 & LIP—HTN & $10.1(16)$ & ART-CAN & $10.0(29)$ & HTN-ART—ARR & $5.3(17)$ & LIP—HTN—ARR & $4.7(30)$ \\
\hline 8 & ART-CAN & $8.8(14)$ & ART-OST & $9.7(28)$ & $\mathrm{HTN}-\mathrm{CAN}-\mathrm{CAD}$ & $5.0(16)$ & LIP-HTN-CAN & $4.5(29)$ \\
\hline 9 & CAN-CAD & $8.8(14)$ & HTN-CKD & $7.6(22)$ & LIP-HTN-CAD & $5.0(16)$ & ART-CAN-OST & $4.4(28)$ \\
\hline 10 & HTN-DEM & $8.8(14)$ & 3-way tiet† & $7.3(21)$ & LIP-ART-CAN & $4.6(15)$ & LIP-HTN-CAD & $3.9(25)$ \\
\hline \multicolumn{9}{|c|}{ 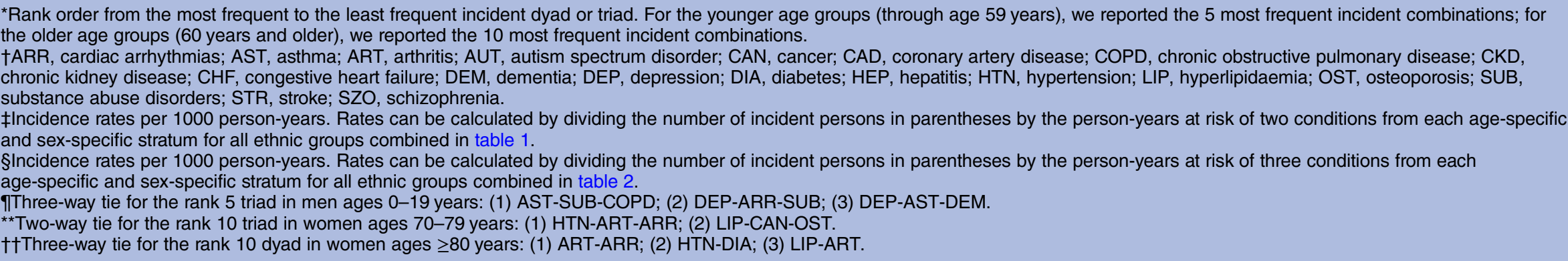 } \\
\hline
\end{tabular}


incident dyad in only 31 persons, and HIV infection in only 41 persons. Therefore, further efforts are needed to refine the list of the most relevant conditions to study multimorbidity, recognising that the most relevant conditions will vary depending on the age and sex of the population.

Some of the dyads and triads derived by the combination of the 20 conditions selected by the US-DHHS may have a much stronger impact on the complexity of clinical management than others. ${ }^{27}$ Therefore, some dyads or triads may be particularly costly for the health system, harder for patients to manage by themselves, less amenable to a single disease approach to care (eg, telemonitoring for heart failure), and may have a stronger effect on functionality, severity of symptoms and risk of death. In addition, social factors (eg, inadequate insurance, low education) and behavioural factors (eg, poor diet) not reflected in the list of 20 US-DHHS conditions may be as important as, or more important than, the 20 conditions in determining the complexity of clinical management and long-term outcomes. ${ }^{27}$

For example, because hyperlipidaemia and hypertension are typically asymptomatic, and are often diagnosed as the result of routine screening, their combination is likely to have a much lower impact on the life of the patient than the combination of schizophrenia and heart failure. However, both combinations are considered multimorbidity by the US-DHHS definition. Our sensitivity analyses highlight this problem. As expected, when hyperlipidaemia and hypertension were considered as a single condition, the overall incidence of multimorbidity decreased. The decreases were relatively small but were more sizeable in men than in women. These findings emphasise the importance of reaching consensus on the list of conditions to be used to define multimorbidity. However, it is difficult to assess the utility of the 20 conditions included in the US-DHHS list without also understanding how different combinations of these conditions impact long term outcomes. Therefore, we plan to continue this initial incidence study with further analyses to assess which combinations of conditions have the greatest impact on adverse outcomes, including patient quality of life and complexity of clinical management. $^{27}$

We defined incident multimorbidity as the date on which a person met the criteria for a second condition or for a third condition. We used an approach similar to that used in the definition of the onset of metabolic syndrome (reaching three of five components of the syndrome). ${ }^{28} 29$ This simple operational definition of incident multimorbidity should be easy to replicate and should facilitate future comparisons with other populations.

Potential limitations of our study include the inability to validate the ICD-9 codes. It was not possible to confirm all diagnoses for the entire study population, and some ICD-9 codes may have been assigned in error (eg, 'rule out' diagnostic codes). To reduce the likelihood of a single ICD-9 code error, we required two or more diagnosis codes separated by more than 30 days for a person to be defined as having a condition. ${ }^{30}$ However, if a person received a valid code and was lost to follow-up or died rapidly after diagnosis, we may have underestimated the incidence of some of the conditions. In addition, we used diagnosis date as a proxy for the true date of onset of the condition.

Some individuals may have moved into Olmsted County after having been diagnosed with one or more chronic conditions elsewhere. If those persons continued to receive care within the REP for a number of years, we captured their chronic condition at the time of subsequent healthcare visits. However, we did not know the true date of onset for the condition, and the sequence of accumulation of conditions could be distorted. Since the population of Olmsted County is stable, particularly among persons who are 40 years of age or older, ${ }^{19}$ we do not expect a major distortion of the multimorbidity incidence rates observed in this study due to migration.

Finally, our study focused on a single geographically defined US population, and the incidence of multimorbidity may differ in other populations. However, the demographic and socioeconomic characteristics of our population are similar to those of the upper Midwest of the $\mathrm{USA},{ }^{20}$ and the prevalence of multimorbidity in persons 65 years of age or older was similar in our population compared with the entire US Medicare population. ${ }^{16}$ Replication of this study in other populations in the USA and worldwide will allow for useful comparisons. ${ }^{31}$

\section{Comparison with other studies}

A number of studies have described the prevalence of multimorbidity in various populations; ${ }^{1}$ 7-12 however, few studies have described the incidence of multimorbidity, and no incidence studies are available for the US. In 1998, van den Akker $e t a l^{32}$ estimated the 1 year incidence of multimorbidity in patients from a network of family practices in the Netherlands. Incident multimorbidity was defined as the new development of at least 2 of 335 diagnostic categories within a 1-year period. Overall, $7.9 \%$ of their population developed one new disease and $1.3 \%$ developed two or more new diseases in 1 year. The proportion of people who developed two or more new conditions increased with older age, but did not differ substantially by sex. It is difficult to compare our results directly to the Dutch findings because of methodological differences (eg, number of conditions considered and time frame), and because it is not clear whether some of the participants in the Dutch study already had one or more conditions at baseline. However, we observed similar patterns of increasing incidence with older age, and limited differences between men and women in overall incidence.

More recently, Melis et $a l^{33}$ assessed the incidence of multimorbidity in Swedish people aged 75 years or older at baseline who participated in a longitudinal cohort 
study. Incident multimorbidity was defined as the development of at least 2 of 39 chronic conditions during 3 years of follow-up. Participants with none of the 39 chronic conditions at baseline had a multimorbidity incidence rate of 12.6 per 100 person-years, and patients with one of the 39 conditions at baseline had an incidence rate of 32.9 per 100 person-years. Although we examined fewer conditions than the Swedish group (20 vs 39), and the ascertainment of incident conditions was different (medical records data vs survey methods), our incidence rates of multimorbidity in participants aged 75 years or older were similar (19.1 per 100 person-years in people with no conditions at baseline and 38.9 per 100 personyears in persons with one condition at baseline; both sexes combined; data not shown).

\section{Meaning of the study}

To understand the importance of these findings, we draw an analogy with the difference between prevalence and incidence in epidemiological studies considering one disease at a time. ${ }^{34}{ }^{35}$ Incidence is the direct measure of the risk of people to develop a given disease, whereas prevalence is the percent of people affected by the same disease at one point in time, and reflects both the effect of incidence and the effect of survival after the onset of the disease. ${ }^{34}{ }^{35}$ Similarly, the prevalence of multimorbidity gives us a static picture of the population; however, prevalence may be misleading when studying the mechanisms of multimorbidity. For example, a higher prevalence of multimorbidity in women than in men may be due to a higher risk of women developing multimorbidity, or to a longer survival of women affected by multimorbidity. ${ }^{16}$ Similarly, studying outcomes among persons with prevalent multimorbidity may be clinically relevant, but may not clarify the outcomes of multimorbidity at the population level (eg, survival bias and inability to study the effect of the duration of multimorbidity).

Prior studies of the prevalence of multimorbidity have shown a dramatic increase in the number of people living with two or more chronic conditions at older ages. ${ }^{17-12}$ However, the high prevalence of multimorbidity in the older population implies that relatively few older individuals remain at risk of developing multimorbidity. Overall, among persons aged 80 years or older at baseline, only 891 out of 3710 (24\%) were at risk of developing two chronic conditions (the other $76 \%$ already had 2 or more of the 20 conditions). Although the persons who reached 80 years of age or older and remained free of multimorbidity were a particularly resilient group, they had a higher risk of developing subsequent multimorbidity compared with younger persons.

We also found that the total number of people who developed multimorbidity before age 65 years was more than four times greater than the number of people who developed multimorbidity at ages 65 or older (28 378 vs 6214). These data emphasise the need to target preventive efforts at much younger ages, but represent only a first step toward future research to identify the social, behavioural and clinical risk and protective factors for multimorbidity.

We found important differences in the incidence of multimorbidity by ethnicity. The age standardised incidence rates of multimorbidity were higher in Blacks and lower in Asians compared to Whites. Our findings are consistent with previous studies that showed a higher prevalence of multimorbidity in Blacks compared to Whites, but a lower prevalence of multimorbidity in Asians. ${ }^{8} 16{ }^{36-38}$ Our data suggest that some of these differences in prevalence may be attributed to differences in the incidence of the conditions among different ethnic groups. However, differential survival may also contribute to the differences in prevalence. In turn, differences in incidence and in prevalence may both be influenced by socioeconomic factors, lifestyle behaviours, social environment and healthcare access. Further research is needed to better characterise these disparities and to identify the causal mechanisms that contribute to different development of chronic conditions and to different survival.

As expected, the incidence and the composition of the dyads and triads of conditions varied extensively across age and sex strata. For example, women 20 years of age or older were more likely to have depression as a component of their incident multimorbidity dyads and triads compared to men. Such differences may lead to different long-term outcomes in men and women. Therefore, these data are useful to understand how multimorbidity develops, and are an important first step toward future research. In particular, such incident data are necessary to study the chronological order of acquisition of multiple chronic conditions in different age, sex and ethnic strata.

Incidence data are also necessary to determine whether the differential order of acquisition is associated with a different risk of adverse long-term outcomes such as hospitalisations, emergency department visits or death. For example, it is not clear whether acquiring depression prior to arthritis results in worse long-term outcomes compared with acquiring arthritis prior to depression. Future studies are also needed to understand how additional chronic conditions accumulate after the development of a second and third condition. Finally, the incidence of specific dyads and triads reflects the incidence of the individual conditions in specific age and sex groups. Many of these dyads and triads are expected to develop simply by chance. Therefore, future studies are needed to identify the dyads and triads that co-occur beyond chance. Identification of incident dyads and triads that reflect shared aetiological mechanisms or shared risk factors may lead to combined treatment or prevention strategies.

\section{Conclusions and clinical implications}

It is important and urgent to understand the causes and the consequences of multimorbidity to inform 
efforts to delay and prevent disease onset, and to develop effective strategies for caring for patients with multimorbidity. We studied the incidence of multimorbidity across all ages, separately in men and women, and in three ethnic groups in a geographically defined US population. The incidence of multimorbidity increased steeply with older age and was higher in Blacks but lower in Asians compared to Whites. Men and women had a similar overall risk, but the combinations of conditions within dyads and triads varied extensively by age and by sex. These data represent an important first step toward identifying conditions that co-occur more frequently than by chance alone, identifying specific risk factors for multimorbidity, understanding how chronic conditions accumulate over time and toward identifying combinations of conditions that predict adverse outcomes.

\section{Author affiliations}

${ }^{1}$ Division of Epidemiology, Department of Health Sciences Research, College of Medicine, Mayo Clinic, Rochester, Minnesota, USA

${ }^{2}$ The Robert $D$ and Patricia E Kern Center for the Science of Health Care Delivery, College of Medicine, Mayo Clinic, Rochester, Minnesota, USA ${ }^{3}$ Division of Geriatric Medicine and Gerontology, Department of Medicine, School of Medicine, Johns Hopkins University, Baltimore, Maryland, USA ${ }^{4}$ Division of Biomedical Statistics and Informatics, Department of Health Sciences Research, College of Medicine, Mayo Clinic, Rochester, Minnesota, USA

${ }^{5}$ Department of Psychiatry and Psychology, College of Medicine, Mayo Clinic, Rochester, Minnesota, USA

${ }^{6}$ Division of Cardiovascular Diseases, Department of Internal Medicine, College of Medicine, Mayo Clinic, Rochester, Minnesota, USA

${ }^{7}$ Department of Research, Olmsted Medical Center, Rochester, Minnesota, USA

${ }^{8}$ Department of Neurology, College of Medicine, Mayo Clinic, Rochester,

Minnesota, USA

Contributors JLS, CMB, BRG, BPY and WAR were involved in study concept and design. JLS, BRG and WAR were involved in acquisition, analysis or interpretation of data. JLS and WAR were involved in drafting of the manuscript. JLS, CMB, BRG, WVB, LJFR, VLR, JOE, TMT, BPY and WAR were involved in critical revision of the manuscript for important intellectual content. BRG and TMT were involved in statistical analysis. BPY and WAR obtained funding and were involved in administrative, technical or material support and study supervision. JLS is the guarantor for the study.

Funding This study was made possible using the resources of the Rochester Epidemiology Project, which is supported by the National Institute on Aging of the National Institutes of Health under Award Number R01AG034676. The content is solely the responsibility of the authors and does not necessarily represent the official views of the National Institutes of Health. This study was also supported by the Mayo Clinic Robert D and Patricia E Kern Center for the Science of Health Care Delivery Population Health Research Programme. CMB was supported by the Paul Beeson Career Development Award Programme (NIA K23 AG032910), the John A Hartford Foundation, Atlantic Philanthropies, the Starr Foundation and an anonymous donor. The authors of this report are responsible for its content.

\section{Competing interests None.}

Ethics approval The study was approved by both the Mayo Clinic (IRB number 1945-99) and the Olmsted Medical Center (IRB number 015-REP-OMC-00) Institutional Review Boards. Since the study only involved review of patient medical record information, the information used in this study was not deemed particularly sensitive, the confidentiality of the information was protected and the study could not practicably be carried out if consent were required, both IRBs waived the requirement for informed consent. However, we only used data from persons who had previously provided a general authorisation for their medical records to be used for research (Minnesota Research Authorization).
Provenance and peer review Not commissioned; externally peer reviewed.

Open Access This is an Open Access article distributed in accordance with the Creative Commons Attribution Non Commercial (CC BY-NC 4.0) license, which permits others to distribute, remix, adapt, build upon this work noncommercially, and license their derivative works on different terms, provided the original work is properly cited and the use is non-commercial. See: http:// creativecommons.org/licenses/by-nc/4.0/

\section{REFERENCES}

1. Salive ME. Multimorbidity in older adults. Epidemiol Rev 2013;35:75-83.

2. Anderson G. Chronic care: making the case for ongoing care. 2010. http://www.rwjf.org/en/research-publications/find-rwjf-research/2010/ 02/chronic-care html (accessed 4 Jun 2014).

3. Vogeli C, Shields AE, Lee TA, et al. Multiple chronic conditions: prevalence, health consequences, and implications for quality, care management, and costs. J Gen Intern Med 2007;22(Suppl 3):391-5.

4. Thorpe KE, Ogden LL, Galactionova K. Chronic conditions account for rise in Medicare spending from 1987 to 2006. Health Aff (Millwood) 2010;29:718-24.

5. Sinnott C, Mc Hugh S, Browne J, et al. GPs' perspectives on the management of patients with multimorbidity: systematic review and synthesis of qualitative research. BMJ Open 2013;3:e003610.

6. Boyd CM, Wolff JL, Giovannetti E, et al. Healthcare task difficulty among older adults with multimorbidity. Med Care 2014;52(Suppl 3): S118-125.

7. Ward BW, Schiller JS. Prevalence of multiple chronic conditions among US adults: estimates from the National Health Interview Survey, 2010. Prev Chronic Dis 2013;10:E65.

8. Lochner KA, Cox CS. Prevalence of multiple chronic conditions among Medicare beneficiaries, United States, 2010. Prev Chronic Dis 2013;10:E61.

9. Ashman JJ, Beresovsky V. Multiple chronic conditions among US adults who visited physician offices: data from the National Ambulatory Medical Care Survey, 2009. Prev Chronic Dis 2013;10:E64.

10. Prados-Torres A, Calderon-Larranaga A, Hancco-Saavedra J, et al. Multimorbidity patterns: a systematic review. J Clin Epidemiol 2014;67:254-66.

11. Barnett K, Mercer SW, Norbury M, et al. Epidemiology of multimorbidity and implications for health care, research, and medical education: a cross-sectional study. Lancet 2012;380:37-43.

12. Weiss CO, Boyd CM, Yu Q, et al. Patterns of prevalent major chronic disease among older adults in the United States. JAMA 2007;298:1160-2

13. Smith SM, Soubhi $\mathrm{H}$, Fortin $\mathrm{M}$, et al. Managing patients with multimorbidity: systematic review of interventions in primary care and community settings. BMJ 2012;345:e5205.

14. Uhlig K, Leff B, Kent D, et al. A framework for crafting clinical practice guidelines that are relevant to the care and management of people with multimorbidity. J Gen Intern Med 2014;29:670-9.

15. US Department of Health and Human Services. Multiple chronic conditions - a strategic framework: optimum health and quality of life for individuals with multiple chronic conditions. Washington DC: US Department of Health and Human Services, 2010.

16. Rocca WA, Boyd CM, Grossardt BR, et al. The prevalence of multimorbidity in a geographically defined American population: patterns by age, sex, and ethnicity. Mayo Clin Proc 2014;89:1336-49.

17. Rocca WA, Yawn BP, St Sauver JL, et al. History of the Rochester Epidemiology Project: half a century of medical records linkage in a US population. Mayo Clin Proc 2012;87:1202-13.

18. St Sauver JL, Grossardt BR, Yawn BP, et al. Use of a medical records linkage system to enumerate a dynamic population over time: the Rochester Epidemiology Project. Am J Epidemiol 2011;173:1059-68.

19. St Sauver JL, Grossardt BR, Yawn BP, et al. Data resource profile: the Rochester Epidemiology Project (REP) medical records-linkage system. Int J Epidemiol 2012;41:1614-24.

20. St Sauver JL, Grossardt BR, Leibson CL, et al. Generalizability of epidemiological findings and public health decisions: an illustration from the Rochester Epidemiology Project. Mayo Clin Proc 2012;87:151-60.

21. Yawn BP, Yawn RA, Geier GR, et al. The impact of requiring patient authorization for use of data in medical records research. J Fam Pract 1998;47:361-5.

22. Jacobsen SJ, Xia Z, Campion ME, et al. Potential effect of authorization bias on medical record research. Mayo Clin Proc 1999;74:330-8. 
23. Goodman RA, Posner SF, Huang ES, et al. Defining and measuring chronic conditions: imperatives for research, policy, program, and practice. Prev Chronic Dis 2013;10:E66.

24. Cohen JW, Cohen SB, Banthin JS. The medical expenditure pane survey: a national information resource to support healthcare cost research and inform policy and practice. Med Care 2009;47(7 Suppl 1):S44-50.

25. Anderson DW, Mantel N. On epidemiologic surveys. Am J Epidemiol 1983;118:613-19.

26. Deming WE. Boundaries of statistical inference. In: Smith $\mathrm{H}$, Johnson NL., eds. New developments in survey sampling. New York: Wiley-Interscience, 1969:652-70.

27. Grant RW, Ashburner JM, Hong CS, et al. Defining patient complexity from the primary care physician's perspective: a cohort study. Ann Intern Med 2011;155:797-804.

28. Palaniappan L, Carnethon MR, Wang Y, et al. Predictors of the incident metabolic syndrome in adults: the Insulin Resistance Atherosclerosis Study. Diabetes Care 2004;27:788-93.

29. Hadaegh $F$, Hasheminia M, Lotfaliany $M$, et al. Incidence of metabolic syndrome over 9 years follow-up; the importance of sex differences in the role of insulin resistance and other risk factors. PLOS ONE 2013;8:e76304.

30. Hebert PL, Geiss LS, Tierney EF, et al. Identifying persons with diabetes using Medicare claims data. Am J Med Qual 1999;14:270-7.
31. Posner SF, Goodman RA. Multimorbidity at the local level: implications and research directions. Mayo Clin Proc 2014;89:1321-3.

32. van den Akker M, Buntinx F, Metsemakers JF, et al. Multimorbidity in general practice: prevalence, incidence, and determinants of co-occurring chronic and recurrent diseases. $J$ Clin Epidemiol 1998;51:367-75.

33. Melis R, Marengoni A, Angleman S, et al. Incidence and predictors of multimorbidity in the elderly: a population-based longitudinal study. PloS ONE 2014;9:e103120.

34. Porta MS, International Epidemiological Association. A dictionary of epidemiology. 5th edn. Oxford; New York: Oxford University Press, 2008.

35. Szklo M, Nieto FJ. Epidemiology: beyond the basics. 2nd edn. Sudbury: Jones and Bartlett Publishers, 2007.

36. Steiner CA, Friedman B. Hospital utilization, costs, and mortality for adults with multiple chronic conditions, Nationwide Inpatient Sample, 2009. Prev Chronic Dis 2013;10:E62.

37. Machlin SR, Soni A. Health care expenditures for adults with multiple treated chronic conditions: estimates from the Medical Expenditure Panel Survey, 2009. Prev Chronic Dis 2013;10:E63.

38. Quinones AR, Liang J, Bennett JM, et al. How does the trajectory of multimorbidity vary across Black, White, and Mexican Americans in middle and old age? J Gerontol B Psychol Sci Soc Sci 2011;66:739-49. 